\title{
CPR1000 核电厂液态流出物排放系统排放能力分析
}

\author{
Discharge Capacity Analysis of Liquid Effluent Discharge System at \\ CPR1000 Nuclear Power Plant \\ 刘军 \\ Jun Liu
}

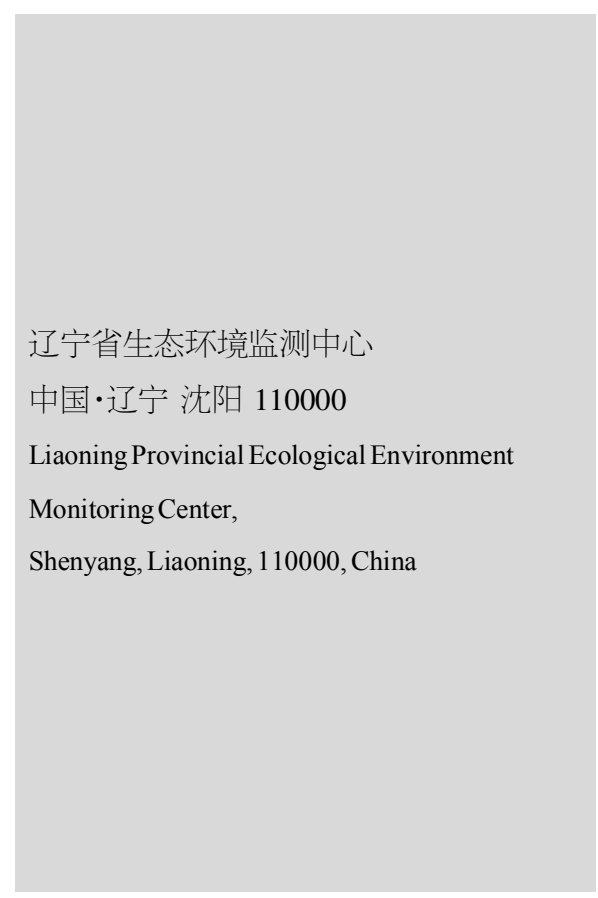

【摘 要】CPR1000 核电厂是以中国广核集团推出的中国改进型百万千瓦级(1000MW)压 水堆核电技术为支撑的核电厂, 液态流出物排放系统是 CPR1000 核电厂的重要模块, 液态 流出物排放系统排放能力可直接影响 CPR1000 核电厂运行安全稳定性。因此, 论文以 CPR1000 核电厂液态流出物排放系统为研究对象, 简要概述了液态流出物排放系统结构, 并对液态流出物排放系统排放能力进行了进一步分析。

【Abstract】CPR1000 nuclear power plant is a nuclear power plant supported by China's improved 1000MW PWR nuclear power technology introduced by China's Guangdong Nuclear Power Group. The liquid effluent discharge system is an important module of CPR1000 nuclear power plant. The discharge capacity of liquid effluent discharge system can directly affect the safety and stability of CPR1000 nuclear power plant. Therefore, this paper takes the liquid effluent discharge system of CPR1000 nuclear power plant as the research object, briefly summarizes the structure of the liquid effluent discharge system, and further analyzes the discharge capacity of the liquid effluent discharge system.

【关键词】CPR1000; 核电厂; 液态流出物排放系统

【Keywords \CPR1000; nuclear power plant; liquid effluent discharge system 【DOI】10.36012/peti.v2i2.1726

\section{1 引言}

CPR1000 核电厂是中国广核集团在吸收、借鉴、消化国外 先进技术经验的基础上,结合多年渐进式改进、自主创新形成 的新型技术一一二代加”百万千瓦级压水堆核电技术, 创建 的新型核电厂, 其在一定程度上解决了日益严峻的能源问题。 而在“二代加”百万千瓦级压水堆核电技术应用背景下, 液态 流出物排放系统逐步朝着规范化、标准化方向发展, 促使核电 站不复以往经过处理满足排放标准后液态流出物直接排人外 界的方式。在这个基础上,对“二代加”百万千瓦级压水堆核电 技术应用背景下液态流出物排放系统排放能力进行分析, 就 成为 CPR1000 核电厂安全平稳运行的关键。

\section{CPR1000 核电厂液态流出物排放系统}

\section{及特点}

“二代加”百万千瓦级压水堆核电技术应用背景下的核电 站液态流出物主要包括常规岛废液、核岛废液两种类型, 其收 集方式、咜存渠道、处理手段均具有一定差异。前者主要通过
常规岛废液它存及排放系统排放, 该系统简称为 SEL; 后者主 要通过核岛废液排放系统排放, 简称为 TER, 其内部具有专 门且独立运行的废液接受槽、废液混匀及取样分析槽、备用 槽, 各槽紧密相连, 可以互为备用 ${ }^{[1]}$ 。

“二代加”百万千瓦级压水堆核电技术应用背景下的核电 站液态流出物排放系统具有基于状态导向的互为备用特征, 可以在减轻操作者负担及人因失误基础上，保证事故情况下 SEL 或 TER 互为备用,降低事故危害性 ${ }^{[2]}$

\section{CPR1000 核电厂液态流出物排放系统} \section{的排放能力分析}

\section{1 排放系统的排放能力分析背景}

CPR1000 核电厂液态流出物排放系统在运行过程中, 对 常规岛废液、核岛废液的排放控制具有较为严格的要求 ${ }^{[3]}$ 。虽 然多数核电站在“二代加”百万千瓦级压水堆核电技术应用时 考虑了严重风险事故发生时放射性流出物包容、滞留情况, 也 采取了一定措施。但是在实际运行过程中, 不可避免地会出现

(下转第 3 页) 
系统的继电保护过程中发挥作用。其之后出现的速断现象可 以有效地保护误动, 即对于未发生故障的元件来说, 其本身已 经不再具有线路运行方面的选择权利。

\section{$335 \mathrm{kV}$ 变电站微电网中分布式电源仿真} 分析

在仅仅有一个分布式电源的系统中, 系统会采取固定功 率的发电机, 一般利用风力发电机作为分布式的电源。35kV 变电站微机中的变压器会具有一定的变比、构线、进线等。研 究人员对不同种类的电源类型进行了科学的仿真分析, 并且 对电气量在不同电源类型中的变化进行了精密的判断和记 录, 其中的观察时间与周期根据相关规定进行设置。

\section{1 同步发电机中电源系统的故障信息判断}

分布式电源系统的故障判断有一定的判断范围, 我们会 在一定时间内进行故障观察, 由于系统中相邻的点之间会有 差别不大的情况, 所以, 当一个地点发生故障时, 我们会对相 邻故障点的电流提供采取主系统提供的方式。当系统中的主系 统容量处在较高水平时, 所给予的短路电流也是较高水平的。 因而,对故障元件的信息判断会更加具有准确性和灵敏性。

\section{2 异步发电机中电源系统的故障信息判断}

在异步电动机中, 我们在进行系统短路的故障判断时, 要 有目的性地对时间故障点和其前后一点孤立的母线之间进行
一定角度和方向的故障判断, 并进行判断依据的记录。当在配 电网中接入分布式电源时, 专业人员会对两种不同接入电源: 异步发电机和同步发电机, 进行不同层次和方面的对比分析, 并且对一定时刻的系统故障进行判断与分析 ${ }^{[2]}$ 。

\section{4 结语}

综上所述, 中国电网系统处在不断升级完善的过程中, $35 \mathrm{kV}$ 变电站微电网逐渐进入人们视线, 分布式电源被接人到 传统配电网中, 使得电网系统面临新的发展方向和道路。我们 要做到的是 $35 \mathrm{kV}$ 变电站微电网的不断融入, 实现其与大网 之间的正确补充, 共同促进未来国家电网的不断发展。以上内 容对中国 $35 \mathrm{kV}$ 变电站微电网网络进行了分析, 对电流故障 与系统工作的相关情况进行了分类介绍，并针对其不同情况 进行了实验分析。为了促进 $35 \mathrm{kV}$ 变电站微电网中配电保护 问题的解决, 提升电网运行水平, 我们需要不断发掘分布式电 源接入的问题, 不断对故障原因进行挖掘, 并进行专业改善, 进行继电保护的仿真, 多方面促进 $35 \mathrm{kV}$ 变电站微机进步。

\section{参考文献}

[1]何䔔. $35 \mathrm{kV}$ 变电站微电网故障分析与保护策略研究 [D].吉林: 东北电力大学, 2012 .

[2]梁明辉,微网故障特性分析和保护原理研究[D].武汉:华中科 技大学,2011.

\section{（上接第 1 页）}

与设计要求不相符的情况。如在 “二代加”百万千瓦级压水堆 核电技术应用影响下的 SEL 部分运行时, 经常出现三伧槽全 部投运情况, 严重违背了 GB 14587-2011《核电厂放射性液 态流出物排放技术要求》要求的“两用一备”原则。同时,在液 态流出物排放系统管理方面, FSAR、EIR 运行要求落实度不 足, 缺乏明确的日常运行管理规定, 影响了液态流出物排放系 统的排放能力。

\section{2 同类机组间排放能力对比}

同类机组间排放类比可以较为清晰地获知 CPR1000 核 电厂液态流出物排放系统的排放能力。因此, 在 CPR 1000 核 电厂液态流出物排放系统的排放能力分析过程中, 可以根据 现有 CPR 1000 核电厂液态流出物排放系统中机组的常规岛 废液咜存及排放系统/核岛废液排放系统设计标准,结合实际 投运的常规岛废液咜存及排放系统/核岛废液排放系统运行 规格, 对国际层面类别一致的机组液态流出物实际排放体积 进行调查。最终结果得出, CPR1000 核电厂液态流出物排放 系统(机组核岛废液排放体积为 5000 12 000 ${ }^{3}$ 、常规岛废液 排放体积为 70000 187 000 m ${ }^{3}$ ) 常规岛、核岛废液排放体积比 为 14.0 15.5; 而法国现有同类机组常规岛废液与核岛废液排 放体积比大约为 4.4(57000/13 000)。由上述结果可知, 中国
CPR1000 核电厂液态流出物排放系统总体与法国同类机组排 放体积一致,但常规岛、核岛废液排放体积比差异较大。

\section{4 结语}

综上所述, 近几年, “二代加”百万千瓦级压水堆核电技术 应用背景下的核电站大批量投运, 导致常规岛废液排放系统 承受着越来越大的压力, 为了切实响应 GB 14587-2011《核 电厂放射性液态流出物排放技术要求》中关于核电站液态流 出物排放系统 “两用一备” 要求, 相关营运单位应在严格执行 报告制度的基础上, 采取恰当措施, 将 TER、SEL 作为应急备 用贬槽, 制定完善的日常运行管理措施, 保证“二代加”百万千 瓦级压水堆核电技术应用背景下的核电站液态流出物排放系 统与 GB 14587-2011《核电厂放射性液态流出物排放技术要 求》要求相符。

\section{参考文献}

[1] 吴连生,曾帆,左伟伟, 等.镍特效树脂分离富集核电厂液态流出 物中的 63Ni 及其测量方法研究[].原子能科学技术, 2018,52(1):30-36.

[2]杨端节, 魏新渝, 方圆, 等. 压水堆核电厂液态流出物排放量统计 方法研究[J]. 辐射防护, 2018,38(3): 186-190.

[3] 覃春丽, 张爱玲, 上官志洪, 等.内陆核电厂液态流出物排放口设 计及环境影响评价初探[J].辐射防护,2017,37(2):121-125. 